\title{
Bacterial adhesion and colonization differences between zirconia and titanium implant abutments: an in vivo human study
}

\author{
Greison Rabelo de Oliveira ${ }^{1}$, Leandro Pozzer², Lucas Cavalieri-Pereira², Paulo Hemerson de Moraes², Sergio Olate ${ }^{3, *}$, \\ Jose Ricardo de Albergaría Barbosa ${ }^{2}$ \\ ${ }^{1}$ Department of Oral and Maxillofacial Surgery, State University of West Paraná, Cascavel, Brazil \\ ${ }^{2}$ Division of Oral and Maxillofacial Surgery, Department of Oral Diagnosis, State University of Campinas Pracicaba Dental School, \\ Piracicaba, Brazil \\ ${ }^{3}$ Division of Oral and Maxillofacial Surgery, Department of Dentristry, University of La Frontera School of Medicine, Temuco, Chile
}

Purpose: Several parameters have been described for determining the success or failure of dental implants. The surface properties of transgingival implant components have had a great impact on the long-term success of dental implants. The purpose of this study was to compare the tendency of two periodontal pathogens to adhere to and colonize zirconia abutments and titanium alloys both in hard surfaces and soft tissues.

Methods: Twelve patients participated in this study. Three months after implant placement, the abutments were connected. Five weeks following the abutment connections, the abutments were removed, probing depth measurements were recorded, and gingival biopsies were performed. The abutments and gingival biopsies taken from the buccal gingiva were analyzed using real-time polymerase chain reaction to compare the DNA copy numbers of Aggregatibacter actinomycetemcomitans, Porphyromonas gingivalis, and total bacteria. The surface free energy of the abutments was calculated using the sessile water drop method before replacement. Data analyses used the Mann Whitney U-test, and P-values below 0.05 find statistical significance.

Results: The present study showed no statistically significant differences between the DNA copy numbers of A. actinomycetemcomitans, P. gingivalis, and total bacteria for both the titanium and zirconia abutments and the biopsies taken from their buccal gingiva. The differences between the free surface energy of the abutments had no influence on the microbiological findings.

Conclusions: Zirconia surfaces have comparable properties to titanium alloy surfaces and may be suitable and safe materials for the long-term success of dental implants.

Keywords: Bacterial adhesion, Dental abutments.

\section{INTRODUCTION}

Numerous studies on various clinical indications have documented high success rates of dental implant therapy [1-4]. Several parameters have been described to determine the success or failure of long-term evaluations of dental implants. Among these, periimplantitis has been proposed to be one of the most critical factors of implant failures [5]. Various experimental $[6,7]$ and clinical studies $[8,9]$ have shown a positive correlation between plaque accumulation and periimplant

Received: Sep. 30, 2012; Accepted: Nov. 25, 2012

*Correspondence: Sergio Olate

Division of Oral and Maxillofacial Surgery, Department of Dentristry, University of La Frontera School of Medicine, Claro Solar 115 Temuco, Araucania, Chile E-mail: solate@ufro.cl, Tel: +56-45-325000, Fax: +56-45-592822 
bone loss. The surface properties of transgingival implant components have a great impact on the long term success of dental implants. Parameters such as surface free energy and, especially, surface roughness were found to be unsupportive in the prevention of plaque accumulation. Therefore, an ideal transmucosal implant surface should be smooth in order to allow the formation of an epithelial seal that prevents plaque accumulation [10-13]. Conventional titanium abutments are widely used as the transgingival components of dental implants [14]. In addition to commercially pure titanium, studies have reported promising results with titanium alloys or with surface modifications of titanium such as coating with titanium nitride $(\mathrm{TiN})$ or zirconium nitride $(\mathrm{ZrN})[10,15]$. In recent years, in order to achieve a final implant-supported prosthesis indistinguishable from the adjacent natural teeth, zirconium abutments have been favored for their aesthetic benefits, especially in the anterior area [16,17]. Zirconia has an excellent resistance to corrosion, biocompatibility, and high levels of loading capacity [18]. The role of specific bacterial species in the pathogenesis of human periodontal diseases has been extensively reviewed, and among these Aggregatibacter actinomycetemcomitans and Porphyromonas gingivalis have been identified as the species most strongly associated with periodontitis and periimplantitis $[19,20]$. These two pathogens have been shown to be able to invade human buccal epithelial cells in vivo [21].

The aim of this study was to compare the tendency of two periodontal pathogens to adhere to and colonize esthetically favorable zirconia abutments and titanium alloys, both on hard surfaces and in soft tissues for 5 weeks after abutment placements.

\section{MATERIALS AND METHODS}

\section{Patient selection}

Twelve patients, 6 women and 6 men, with a mean age of 47 years (standard deviation, 10 years) who were referred for treatment at the Piracicaba Dental School, were selected based on the following inclusion criteria: 1) the presence of partial edentulism with reduced stability and chewing ability, 2) no history of radiotherapy in the head and neck region, 3) no history of preprosthetic surgery or previously inserted implants, and 4) no history of systematic disease, smoking habit, or pregnancy. This study was approved by the Institutional Ethics Board for human subjects, and each patient received a detailed description of the proposed treatment for informed consent. All of the patients received two implants. Three months after surgery, two different types of abutment connections, titanium and zirconium abutments, were performed. The placement of the abutment types were selected randomly for each patient, but in order to avoid the differences in plaque control between the mesial and distal areas, a great effort was made to equally distribute the zirconium and titanium abutments on the dental arch according to their mesial or distal location ( 6 zirconium and 6 titanium abutments were located in the anterior region). After 5 weeks of abutment connections, the abutments were removed, the probing depth measurements were recorded, and gingival biopsies were performed. The abutments and gingival biopsies were analyzed by microbiological evaluations. After removal of the abutments, gingival formers were placed in each patient.

\section{Clinical and radiographic measurements}

All examinations were conducted by a single, experienced dental examiner. The full mouth plaque index scores, gingival index scores, probing depth measurements, and bleeding on probing scores were recorded for each patient during the initial therapy. Full mouth periapical and panoramic radiographies were also performed. The patients with chronic or aggressive periodontitis were excluded from the study. All of the patients' teeth were stained for plaque and received a thorough supragingival dental prophylaxis to remove all the stains, calculus, and plaque. Detailed oral hygene instructions were also provided to the patients. After 4 weeks of initial therapy, all of the measurements were recorded again, and oral hygene procedures were repeated as needed. At the end of the following week, the surgical procedures were performed. The clinical measurements were obtained during the initial visits, before surgery, and five weeks after surgery, as described in the following section. Full-mouth probing measurements were recorded at the mesiobuccal, midbuccal, distobuccal, mesiolingual, midlingual, and distolingual surfaces using a Williams probe. The probing depth was assessed as the longest distance between the gingival margin and the base of the periodontal pocket, and the gingival recession was assessed as the longest distance between the cemento-enamel junction and the gingival margin. The full-mouth gingival index (Löe \& Silness) and plaque index (Silness \& Löe) were also determined. Bleeding on probing was recorded as positive if it occurred within 30 seconds of probing.

\section{Surgical procedures}

Following local anesthesia, crestal incisions were made and a full-thickness flap was elevated. All the patients received two implants in the premolar or molar region of the mandible. The surgical procedure followed the manufacture's recommendation. Following the site preparation, two implants were placed on the mandible. The surgical flaps were sutured with nonresorbable sutures. Unless contraindicated, all the patients were prescribed a nonsteroidal antiinflammatory 
(200 mg flurbiprofen) and chlorhexidine rinse. The sutures were removed one week postoperatively.

Three months after the implant placement, second-stage surgeries were performed and the abutments were connected. Five weeks following the abutment connections, the patients were instructed to brush their abutments and teeth twice daily, but they were not allowed to use any type of interdental cleaners. After 5 weeks of abutment connections, the abutments were removed, the probing depth measurements were recorded, and gingival biopsies were performed. The abutments and gingival biopsies taken from the abutments in the buccal gingiva were analyzed using real-time polymerase chain reaction (PCR) to compare the DNA copy numbers of $A$. actinomycetemcomitans, $P$. gingivalis, and total bacteria. The surface free energy of the abutments were calculated using sessile water drops before the replacement, and this data helped us to explicate the real-time PCR findings.

\section{Measurement of surface free energy}

In order to estimate the wetting of the abutment surfaces, the sessile drop technique was used. The titanium and zirconium abutment surfaces were wetted with $2 \mu \mathrm{L}$ of deionized water. The sessile drop was visualized using a charge coupled device camera (CCD-C) for acquisition image, and the contact angle was measured using Image 1.46 software (National Institute of Health, Bethesda, MD, USA) [22], with a framework analysis routine technique. The surface hydrophobicity of the abutments was expressed as the work of adhesion between a solid and liquid and calculated using the Young-Dupre equation, $-\Delta \mathrm{GSL}=\gamma \mathrm{L}(1+\operatorname{Cos} \theta)$ [23], where liquid interfacial free en$\operatorname{ergy}(\gamma \mathrm{L})$ for deionized water was accepted as $7.2 \times 10^{-4} \mathrm{~N} . \mathrm{m}^{-1}$ at $25^{\circ}[24]$ and $\theta$ is the contact angle of the sessile water drop.

\section{DNA isolation and purification from the zirconium and titanium abutment surfaces and the corresponding mucosal biopsy samples}

The abutments and mucosal samples were treated for 3 hours with digestion buffer, which contained proteinase $\mathrm{K}$ and sodium dodecyl sulfate. The lysates were mixed with guanidium thiocyanate containing binding buffer, and then loaded to the silica spin columns. After the binding step, the silica bound DNA samples were washed with ethanol-tris-chloride buffer in order to wash off the excess salt. DNA was eluted using a $10 \mathrm{mM}$ Tris chloride $\mathrm{pH} 9.0$ buffer.

\section{Detection and quantification of A. actinomycetemcomitans, P. gingivalis, and total bacterial DNA using real-time PCR}

Real-time PCR with 5 ' hydrolysis chemistry was used to detect and quantify total bacteria, A. actinomycetemcomitans, and P. gingivalis DNA. The oligonucleotide primers and fluorescent labeled probes used in this study are shown in Table 1 [25]. Fluorometric real-time PCR was performed in a $25 \mu \mathrm{L}$ reaction mix consisting of the ready-to-use TaqMan Universal Master Mix (Applied Biosystems, Foster City, CA, USA), 0.5 $\mu \mathrm{M}$ of each primer, and $0.15 \mu \mathrm{M}$ of the 5 hydrolysis probe. Cycling conditions were set as initial denaturation and enzyme activation at $95^{\circ} \mathrm{C}$ for 10 minutes, followed by 40 cycles of denaturation at $95^{\circ} \mathrm{C}$ for 15 seconds and elongation at $60^{\circ} \mathrm{C}$ for $1 \mathrm{~min}$ ute. The fluorometric readings were performed at the elongation step. The cloned DNA standards of 100 to 107 copies/ $\mu \mathrm{L}$ were used to construct the quantification curve.

\section{Statistical evaluation}

The differences between the implant groups were evaluated using the nonparametric Mann-Whitney U-test. P-values below 0.05 were considered statistically significant. The values of the clinical and biochemical parameters are expressed as mean \pm standard error of mean $(\mathrm{SEM})$.

\section{RESULTS}

\section{Surface free energy}

The surface free energy of the abutments was calculated using the sessile water drop method. Comparing the surface

Table 1. Oligonucleotide primers and fluorescent labelled 5' exonuclease probes used in the study.

\begin{tabular}{lll}
\hline Bacteria & Primer & \multicolumn{1}{c}{ Base squence } \\
\hline Universal bacterial (Uni) & Uni152-f & 5'-cgctagtaatcgtggatcagaatg-3' $^{\prime}$ \\
Aggregatibacter actinomycetemcomitans (Aa) & Uni220-r & $5^{\prime}$-'tgtgacgggcggtgtgta-3' \\
& Uni177T & $5^{\prime}$-JOE-cacggtgaatacgttcccgggc-TAMRA-3' \\
Porhyromonas gingivalis (Pg) & Aa-f & $5^{\prime}$-acgcagacgattgactgaatttaa-3' \\
& Aa-r & $5^{\prime}$-gatcttcacagctatatggcagcta-3' \\
& Aa-S & $5^{\prime}$-FAM-tcacccttctaccgttgccatggg-TAMRA-3' \\
& Pg-f & $5^{\prime}$-cctacgtgtacggacagagctata -3' \\
\hline
\end{tabular}




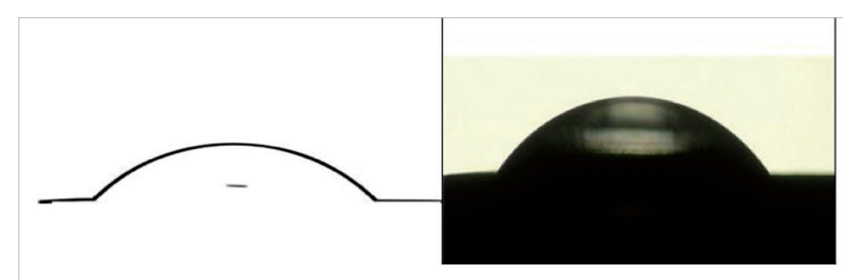

Figure 1. The angular value of titanium abutment obtained by sessile water drop: $129.08^{\circ}$.

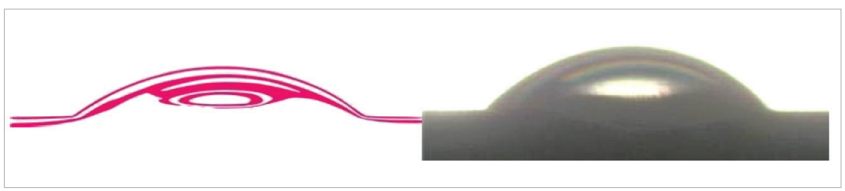

Figure 2. The angular value of zirconium abutment obtained by sessile water drop: $137.99^{\circ}$.

free energy of the zirconia and titanium abutments, the zirconia abutments showed lower surface free energy than the

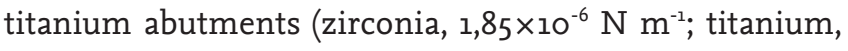
$2,662 \times 10^{-6} \mathrm{~N} \mathrm{~m}^{-1}$ ) (Figs. 1 and 2).

\section{Microbiological analysis and probing depth}

No significant differences were found in the DNA copy numbers of the adherent total bacteria, A. actinomycetemcomitans, or P. gingivalis for both the titanium and zirconia abutment surfaces and also for the biopsies taken from their buccal gingiva $(P>0.05)$. The differences between the free surface energy of the abutments had no influence on the microbiological findings (Tables 1-3). The results of the MannWhitney $U$-test indicated that the differences between the implant groups were not significant $(P=0.388)$ for probing depth, with the titanium surface at $2.51 \pm 0.13 \mathrm{~mm}$ and the zirconium surface at $2.38 \pm 0.09 \mathrm{~mm}$.

\section{DISCUSSION}

The present study has shown no statistically significant differences between the DNA copy numbers of A. actinomycetencomitans, P. gingivalis, and total bacteria for both the titanium and zirconia abutments and the biopsies taken from their buccal gingiva (Figs. 3 and 4). The differences between the free surface energy of the abutments had no influence on the microbiological findings. After the experimental studies of Loe et al. [26] that pointed out biofilm as a primer etiologic factor responsible for gingivitis or periodontitis, numerous clinical, histological, and microbiological studies revealed a similar nature of periodontitis and periimplantitis $[6,7,27]$. The lack of a cement layer and Sharpey's fiber on the
Table 2. Log total bacterial, Aggregatibacter actinomycetemcomitans and Porhyromonas gingivalis DNA copy numbers $/ \mu \mathrm{L}$ in titanium and zirconia abutments.

\begin{tabular}{lccc}
\hline & Titanium & Zirconium & $P$-value \\
\hline $\begin{array}{l}\text { Total bacteria log DNA copy } \\
\text { numbers } / \mu \mathrm{L}\end{array}$ & $6.07 \pm 0.12$ & $6.12 \pm 0.12$ & 0.6949 \\
$\begin{array}{l}\text { A. actinomycetemcomitans log } \\
\text { DNA copy numbers/ } \mu \mathrm{L}\end{array}$ & $1.67 \pm 0.14$ & $1.43 \pm 0.12$ & 0.5002 \\
$\begin{array}{l}\text { P. gingivalis log DNA copy } \\
\text { numbers } / \mu \mathrm{L}\end{array}$ & $3.34 \pm 0.18$ & $3.65 \pm 0.17$ & 0.7671 \\
\hline
\end{tabular}

Values are presented as mean \pm standard deviation.

Table 3. Log total bacterial, Aggregatibacter actinomycetemcomitans and Porhyromonas gingivalis DNA copy numbers $/ \mu \mathrm{L}$ in buccal gingiva biopsies adjacent to titanium and zirconia abutments.

\begin{tabular}{lccc}
\hline & Titanium & Zirconium & $P$-value \\
\hline $\begin{array}{c}\text { Total bacteria log DNA copy } \\
\text { numbers/ } \mu \mathrm{L}\end{array}$ & $4.59 \pm 0.13$ & $3.65 \pm 0.13$ & 0.2719 \\
$\begin{array}{l}\text { A. actinomycetemcomitans log } \\
\text { DNA copy numbers/ } \mu \mathrm{L}\end{array}$ & $1.24 \pm 0.11$ & $0.33 \pm 0.07$ & 0.0796 \\
$\begin{array}{l}\text { P. gingivalis } \log \text { DNA copy } \\
\text { numbers } / \mu \mathrm{L}\end{array}$ & $1.29 \pm 0.14$ & $1.92 \pm 0.15$ & 0.3454 \\
\hline
\end{tabular}

Values are presented as mean \pm standard deviation.

implant surfaces makes the ephitelial downgrowth occur faster than natural teeth [28]. Because of this, the transgingival implant components seem to be particularly important with regard to the plaque accumulation properties, which are essential for the prevention of failures.

In the past decades, much attention has been focused on the zirconium ceramic, which combines biocompatibility, aesthetics, and impressive resistance to fractures $[13,16,17]$. Understanding the influence of zirconium surfaces on bacterial colonization and plaque formation is important for verifying the reliability of zirconia surfaces.

It has been reported that the surface roughness of implant materials has a significant impact on plaque formation [29, 30]. Smooth surfaces have been suggested for resisting bacterial colonazition [10]. Comparing the surface roughness of commercially pure titanium surfaces with the Ti6 $\mathrm{Al}_{4} \mathrm{~V}$ surfaces used in our study, the roughness of the Ti6 $\mathrm{Al}_{4} \mathrm{~V}$ surfaces were found to be significantly lower than that of the commercially pure titanium surfaces [31], suggesting that titanium alloys may harbor fewer bacteria.

Rimondini et al. [13] compared oral bacterial colonization on machined grade $2 \mathrm{Ti}$ (commercially pure titanium) and tetragonal zirconia polycrystal stabilized yttrium (Y-TZP) fabricated disks in vitro and in vivo. The in vivo tetragonal zirconia, stabilized with yttrium surfaces, accumulated significantly fewer bacteria than titanium, whereas no differences were 

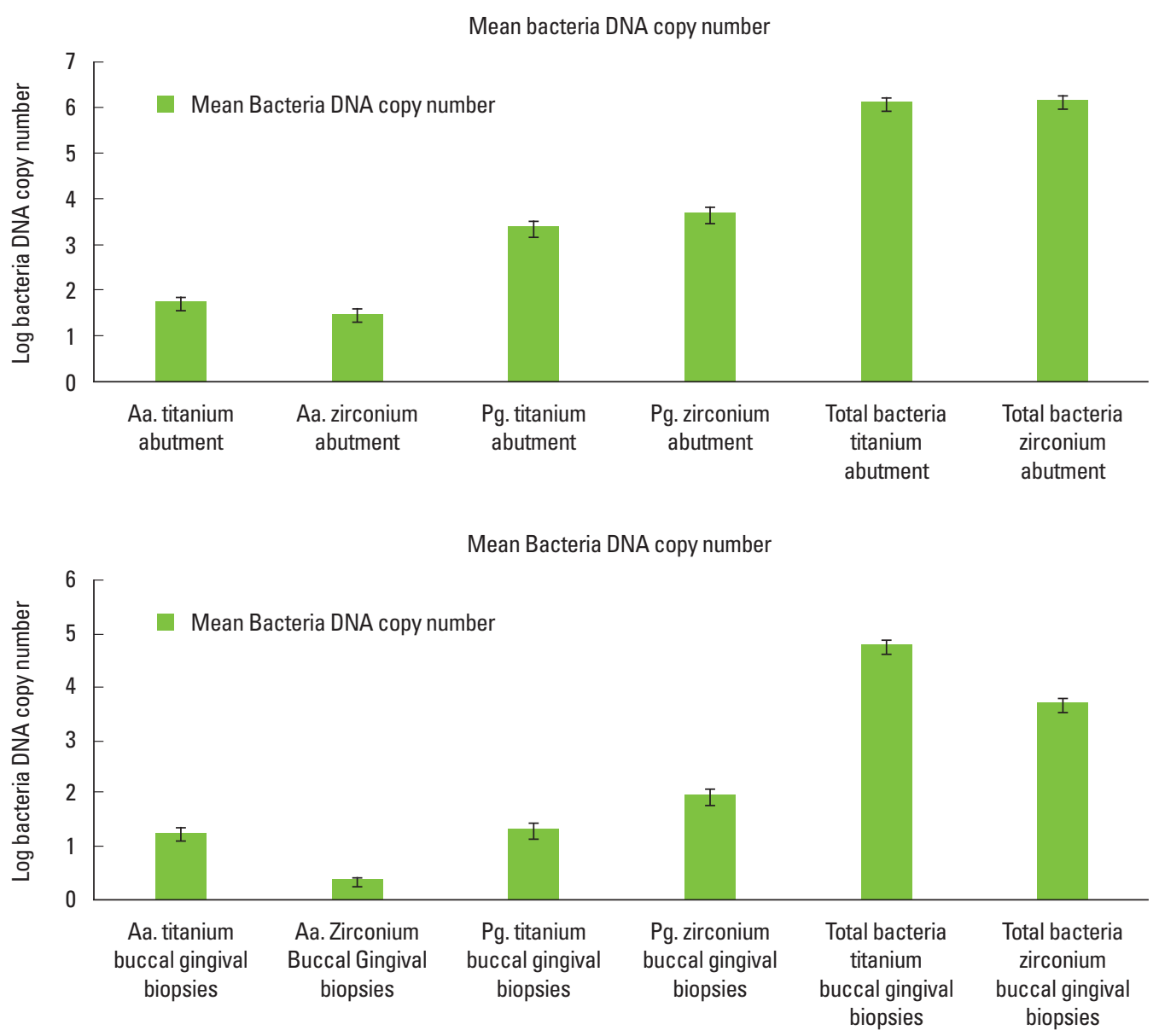

Figure 3. DNA copy numbers of titanium and zirkonium abutments. Aa.: Aggregatibacter actinomycetemcomitans, Pg.: Porphyromonas gingivalis.
Figure 4. DNA copy numbers of buccal gingival biopsies of titanium and zirkonium abutments. Aa.: Aggregatibacter actinomycetemcomitans, Pg.: Porphyromonas gingivalis. noted for Actinomyces spp. or P. gingivalis in vitro. Scarano et al. [17] evaluated the microbiologic characteristics of commercially pure titanium (control) and zirconia (test) disks for 24 hours in ten patients. A removable acrylic device was adapted to the molar-premolar region, and was glued to the buccal aspect of each device. SEM analysis showed that in the zirconium disks, the area covered by bacteria was $12.1 \%$, whereas in the titanium disks, the area covered by bacteria was $19.3 \%$. Both of the studies mentioned above were short-term evaluations (24 hours), and they did not evaluate the subgingival area. In addition, the abutments used in these studies were of commercially pure titanium. In our study we investigated bacterial colonization for 5 weeks, not only on the zirconium and titanium abutment surfaces, but also in the gingival biopsies directly adjacent to the abutment surfaces.

Grossner-Schreiber et al. [10] evaluated bacterial adhesion on four different surface treatments: physical vapor deposition with either TiN or $\mathrm{ZrN}$, thermal oxidation, and structuring with laser radiation. Polished titanium surfaces were used as controls. Compared to polished titanium, the authors reported a significant reduction in the number of adherent bacteria on inherently stable titanium hard materials such as
TiN and ZrN and thermically oxidated titanium surfaces and concluded that physical modification of titanium implant surfaces, such as coating with TiN or $\mathrm{ZrN}$, may reduce bacterial adherence and thus improve clinical results. The titanium alloys (Ti6Al4V) used in our study showed comparable results with the zirconium abutments.

Quirynen et al. [32] compared the influence of surface free energy of conventional titanium abutments and fluor-ethylene-propylene (FEP)-coated abutments on supra- and subgingival plaque microbiology in 9 patients. The supragingival plaque was examined using differential phase-contrast microscopy and showed that the FEP coated abutments, which had lower surface free energy, frequently harbored more coccoid microorganisms, whereas spirochetes or motile organisms were only detected around the titanium abutments, which had higher surface free energy. Subgingivally, for the abutment-adhering plaque, the number of colony forming units was higher on the titanium abutments than on the FEP-coated abutments. However, this difference was not statistically significant $(P=0.38)$. When comparing the surface free energies of the titanium and zirconia abutments used in our study, the zirconia abutments had lower surface free en- 
ergy than the titanium abutments $\left(18.50 \mathrm{erg} / \mathrm{cm}^{2}\right.$ vs. 26.62 $\left.\mathrm{erg} / \mathrm{cm}^{2}\right)$, suggesting that the zirconium abutments would harbor fewer bacteria than the titanium abutments. In fact, the real-time PCR analysis of the gingival biopsies showed fewer A. actinomycetencomitans DNA copy numbers with the zirconia abutments, but these differences were not statistically significant $(P=0.0796)$.

In conclusion, the results of this research showed that zirconia surfaces had comparable properties to titanium alloy surfaces, both supragingivally on the abutments and in buccal gingival biopsies related to the subgingival area.

\section{CONFLICT OF INTEREST}

No potential conflict of interest relevant to this article was reported.

\section{REFERENCES}

1. Branemark PI, Hansson BO, Adell R, Breine U, Lindstrom $\mathrm{J}$, Hallen $\mathrm{O}$, et al. Osseointegrated implants in the treatment of the edentulous jaw. Experience from a 10-year period. Scand J Plast Reconstr Surg Suppl 1977;16:1-132.

2. Buser D, Mericske-Stern R, Bernard JP, Behneke A, Behneke N, Hirt HP, et al. Long-term evaluation of non-submerged ITI implants. Part 1: 8-year life table analysis of a prospective multi-center study with 2359 implants. Clin Oral Implants Res 1997;8:161-72.

3. Buser D, Weber HP, Lang NP. Tissue integration of nonsubmerged implants. 1-year results of a prospective study with 100 ITI hollow-cylinder and hollow-screw implants. Clin Oral Implants Res 1990;1:33-40.

4. Heijdenrijk K, Raghoebar GM, Meijer HJ, Stegenga B, van der Reijden WA. Feasibility and influence of the microgap of two implants placed in a non-submerged procedure: a five-year follow-up clinical trial. J Periodontol 2006;77: 1051-60.

5. Oh TJ, Yoon J, Misch CE, Wang HL. The causes of early implant bone loss: myth or science? J Periodontol 2002; 73:322-33.

6. Lindhe J, Berglundh T, Ericsson I, Liljenberg B, Marinello C. Experimental breakdown of peri-implant and periodontal tissues. A study in the beagle dog. Clin Oral Implants Res 1992;3:9-16.

7. Lang NP, Bragger U, Walther D, Beamer B, Kornman KS. Ligature-induced peri-implant infection in cynomolgus monkeys. I. Clinical and radiographic findings. Clin Oral Implants Res 1993;4:2-11.

8. Becker W, Becker BE, Newman MG, Nyman S. Clinical and microbiologic findings that may contribute to dental implant failure. Int J Oral Maxillofac Implants 1990;5:31-8.

9. Sumida S, Ishihara K, Kishi M, Okuda K. Transmission of periodontal disease-associated bacteria from teeth to osseointegrated implant regions. Int J Oral Maxillofac Implants 2002;17:696-702.

10. Grossner-Schreiber B, Griepentrog M, Haustein I, Muller $\mathrm{WD}$, Lange $\mathrm{KP}$, Briedigkeit $\mathrm{H}$, et al. Plaque formation on surface modified dental implants. An in vitro study. Clin Oral Implants Res 2001;12:543-51.

11. Bollen CM, Papaioanno W, Van Eldere J, Schepers E, Quirynen $M$, van Steenberghe D. The influence of abutment surface roughness on plaque accumulation and peri-implant mucositis. Clin Oral Implants Res 1996;7:201-11.

12. Binon PP. Implants and components: entering the new millennium. Int J Oral Maxillofac Implants 2000;15:76-94.

13. Rimondini L, Cerroni L, Carrassi A, Torricelli P. Bacterial colonization of zirconia ceramic surfaces: an in vitro and in vivo study. Int J Oral Maxillofac Implants 2002;17:793-8.

14. Lautenschlager EP, Monaghan P. Titanium and titanium alloys as dental materials. Int Dent J 1993;43:245-53.

15. Steinberg D, Sela MN, Klinger A, Kohavi D. Adhesion of periodontal bacteria to titanium, and titanium alloy powders. Clin Oral Implants Res 1998;9:67-72.

16. Piconi C, Maccauro G. Zirconia as a ceramic biomaterial. Biomaterials 1999;20:1-25.

17. Scarano A, Piattelli M, Caputi S, Favero GA, Piattelli A. Bacterial adhesion on commercially pure titanium and zirconium oxide disks: an in vivo human study. J Periodontol 2004;75:292-6.

18. Heuer W, Elter C, Demling A, Neumann A, Suerbaum S, Hannig $M$, et al. Analysis of early biofilm formation on oral implants in man. J Oral Rehabil 2007;34:377-82.

19. Consensus report. Periodontal diseases: pathogenesis and microbial factors. Ann Periodontol 1996;1:926-32.

20. van Winkelhoff AJ, Goene RJ, Benschop C, Folmer T. Early colonization of dental implants by putative periodontal pathogens in partially edentulous patients. Clin Oral Implants Res 2000;11:511-20.

21. Rudney JD, Chen R, Sedgewick GJ. Intracellular Actinobacillus actinomycetemcomitans and Porphyromonas gingivalis in buccal epithelial cells collected from human subjects. Infect Immun 2001;69:2700-7.

22. Image J [nternet]. Bethesda: National Institutes of Health; [c2012] [2012 Apr 4]. Available from: http://rsbweb.nih.gov/ ij/.

23. van Oss CJ. Interfacial forces in aqueous media. 2nd ed. Boca Raton: Talyor \& Francis; 2006.

24. Wei YH, Lai HC, Chen SY, Yeh MS, Chang JS. Biosurfactant production by Serratia marcescens SS-1 and its isogenic strain SMdeltaR defective in SpnR, a quorum-sens- 
ing LuxR family protein. Biotechnol Lett 2004;26:799-802. 25. Lau L, Sanz M, Herrera D, Morillo JM, Martin C, Silva A. Quantitative real-time polymerase chain reaction versus culture: a comparison between two methods for the detection and quantification of Actinobacillus actinomycetemcomitans, Porphyromonas gingivalis and Tannerella forsythensis in subgingival plaque samples. J Clin Periodontol 2004;31:1061-9.

26. Loe $\mathrm{H}$, Theilade $\mathrm{E}$, Jensen SB. Experimental gingivitis in man.J Periodontol 1965;36:177-87.

27. Hickey JS, O’Neal RB, Scheidt MJ, Strong SL, Turgeon D, Van Dyke TE. Microbiologic characterization of ligatureinduced peri-implantitis in the microswine model. J Periodontol 1991;62:548-53.

28. Berglundh T, Lindhe J, Marinello C, Ericsson I, Liljenberg B. Soft tissue reaction to de novo plaque formation on implants and teeth. An experimental study in the dog. Clin Oral Implants Res 1992;3:1-8.

29. Quirynen M, Marechal M, Busscher HJ, Weerkamp AH,
Darius PL, van Steenberghe D. The influence of surface free energy and surface roughness on early plaque formation. An in vivo study in man. J Clin Periodontol 1990;17: 138-44.

30. Quirynen M, van der Mei HC, Bollen CM, Schotte A, Marechal M, Doornbusch GI, et al. An in vivo study of the influence of the surface roughness of implants on the microbiology of supra- and subgingival plaque. J Dent Res 1993; 72:1304-9.

31. Guilherme AS, Henriques GE, Zavanelli RA, Mesquita MF. Surface roughness and fatigue performance of commercially pure titanium and $\mathrm{Ti}-6 \mathrm{Al}-4 \mathrm{~V}$ alloy after different polishing protocols. J Prosthet Dent 2005;93:378-85.

32. Quirynen M, Van der Mei HC, Bollen CM, Van den Bossche LH, Doornbusch GI, van Steenberghe D, et al. The influence of surface-free energy on supra- and subgingival plaque microbiology. An in vivo study on implants. J Periodontol 1994;65:162-7. 